\title{
The air that we (do not) breathe: lower adipose tissue oxygen availability in patients with obesity hypoventilation syndrome?
}

\author{
Gijs H. Goossens $\mathbb{B D}^{1}$
}

Received: 11 February 2021 / Revised: 23 February 2021 / Accepted: 23 February 2021 / Published online: 23 March 2021

(c) The Author(s), under exclusive licence to Springer Nature Limited 2021

Alterations in adipose tissue (AT) oxygen partial pressure $\left(\mathrm{pO}_{2}\right)$, resulting from perturbations in the balance between AT oxygen delivery and oxygen consumption, have been implicated in the pathophysiology of obesity-related cardiometabolic complications [1]. However, previous studies have yielded conflicting results, showing that $\mathrm{AT}_{\mathrm{pO}}$ was lower [2-4] and higher [5, 6] in people with obesity compared with people with normal body weight. These inconsistent findings may be explained by differences in study populations and methodology.

I have read with great interest the article by Todorčević and colleagues [7] in this issue of the International Journal of Obesity, in which the authors aimed to further evaluate whether 'hypoxia' is present in abdominal subcutaneous AT in people with obesity. The team of investigators determined protein expression of hypoxia-inducible factor- $1 \alpha$ (HIF1A), which acts as a molecular oxygen sensor [8], and several hypoxia-responsive genes in people with normal weight, class I obesity (BMI $30-34.9 \mathrm{~kg} / \mathrm{m}^{2}$ ) and class III obesity $\left(\mathrm{BMI}>40 \mathrm{~kg} / \mathrm{m}^{2}\right)$. As proof-of-concept, a group of individuals with class III obesity and obesity hypoventilation syndrome (OHS) was also included. OHS is a form of sleep-disordered breathing in which people with severe overweight/obesity fail to breathe rapidly or deeply enough due to excessive AT and a blunted ventilatory response, resulting in low systemic oxygen levels $\left(\mathrm{SpO}_{2}\right)$ and high carbon dioxide levels. Todorčević and colleagues [7] dichotomized the people with class III obesity with versus without OHS based on the proportion of sleeping time spent below $\mathrm{SpO}_{2}$ of $90 \%$.

Gijs H. Goossens

G.Goossens@maastrichtuniversity.nl

1 Department of Human Biology, NUTRIM School of Nutrition and Translational Research in Metabolism, Maastricht University Medical Centre+, Maastricht, The Netherlands
The authors found that HIF1A protein levels were higher in abdominal subcutaneous AT of people with class III obesity and OHS than those with class I obesity and normal weight, whereas people with class III obesity without OHS showed intermediate HIF1A protein expression. Thus, Todorčević and colleagues [7] conclude that AT hypoxia is present in patients with class III obesity and OHS but not in people with class III obesity without OHS and those with moderate obesity, and suggest that AT dysfunction may not be driven by hypoxia in people with obesity without OHS.

Yet, some important issues remain to be elucidated. First, direct monitoring of $\mathrm{AT} \mathrm{pO}_{2}$ would have provided important information about absolute differences in AT $\mathrm{pO}_{2}$ between study groups and heterogeneity within groups. Importantly, since HIF1A protein levels do not seem to show a linear relationship with $\mathrm{AT} \mathrm{pO}_{2}$ [9], it could be argued that modest but physiologically relevant differences in AT $\mathrm{pO}_{2}$ may not be detectable using HIF1A protein expression as experimental read-out. Notably, differences in the severity of oxygen desaturation, the pattern of hypoxic cycles as well as the time between the last hypoxic episode and collection of the AT biopsy may have influenced HIF1A protein levels. In addition, although HIF-1A expression is modulated by cellular $\mathrm{pO}_{2}$, it seems that cytokines, reactive oxygen species and growth factors may also affect HIF-1A expression [8]. Because of this, and the fact that HIF1A protein abundance was assessed in a small number of people, these findings require confirmation in a larger study population.

Second, the present study does unfortunately not provide evidence for a causal relationship between higher AT HIF-1A protein expression, AT dysfunction and/or the metabolic phenotype in individuals with class III obesity and OHS. More detailed assessment of the AT phenotype, including measurements of AT blood flow, adipocyte size and mitochondrial function markers, would have provided further insight into the biological 
basis as well as possible consequences of increased HIF$1 \mathrm{~A}$ levels in these patients.

The novel findings by Todorčević and colleagues [7] contribute to the ongoing debate whether $\mathrm{AT}_{\mathrm{pO}}$ is altered in people with (severe) obesity. To better understand the conflicting findings on $\mathrm{AT} \mathrm{pO}_{2}$ in human obesity, future studies are warranted to investigate the relationship between AT $\mathrm{pO}_{2}$ and age, obesity history (i.e., obesity duration and weight cycling), metabolic phenotype, as well as sexual dimorphism in the etiology of obesity-related cardiometabolic complications [10]. I believe our research efforts should now move from exploring associations to establishing causation. Thus, experiments in primary human adipocytes, myocytes and hepatocytes that are cultured under different oxygen levels mimicking the local tissue microenvironment will reveal whether and how perturbations in tissue oxygenation affect the metabolic and/or inflammatory phenotype. This, together with wellcontrolled human intervention studies investigating the impact of hypoxia/hyperoxia exposure on $\mathrm{AT} \mathrm{pO}_{2}$ and metabolic outcomes, will provide a breath of fresh air in the efforts to better understand the importance of tissue oxygenation in obesity-related cardiometabolic complications, and may help to develop novel treatment avenues to prevent and treat obesity-related chronic diseases.

\section{Compliance with ethical standards}

Conflict of interest The author declares no competing interests.

Publisher's note Springer Nature remains neutral with regard to jurisdictional claims in published maps and institutional affiliations.

\section{References}

1. Lempesis IG, van Meijel RLJ, Manolopoulos KN, Goossens GH. Oxygenation of adipose tissue: A human perspective. Acta Physiol. 2020;228:e13298.

2. Cifarelli V, Beeman SC, Smith GI, Yoshino J, Morozov D, Beals JW, et al. Decreased adipose tissue oxygenation associates with insulin resistance in individuals with obesity. J Clin Invest. 2020;130:6688-99.

3. Lawler HM, Underkofler CM, Kern PA, Erickson C, Bredbeck B, Rasouli N. Adipose tissue hypoxia, inflammation, and fibrosis in obese insulin-sensitive and obese insulin-resistant subjects. J Clin Endocrinol Metab. 2016;101:1422-8.

4. Pasarica M, Rood J, Ravussin E, Schwarz JM, Smith SR, Redman LM. Reduced oxygenation in human obese adipose tissue is associated with impaired insulin suppression of lipolysis. J Clin Endocrinol Metab. 2010;95:4052-5.

5. Goossens GH, Bizzarri A, Venteclef N, Essers Y, Cleutjens JP, Konings $\mathrm{E}$, et al. Increased adipose tissue oxygen tension in obese compared with lean men is accompanied by insulin resistance, impaired adipose tissue capillarization, and inflammation. Circulation. 2011;124:67-76.

6. Goossens GH, Vogel MAA, Vink RG, Mariman EC, van Baak MA, Blaak EE. Adipose tissue oxygenation is associated with insulin sensitivity independently of adiposity in obese men and women. Diabetes Obes Metab. 2018;20:2286-90.

7. Todorčević M, Manuel AR, Austen L, Michailidou Z, Hazlehurst JM, Neville MJ, et al. Markers of adipose tissue hypoxia are elevated in subcutaneous adipose tissue of severely obese patients with obesity hypoventilation syndrome but not in the moderately obese. Int J Obes. 2021, https://doi.org/10.1038/s41366-021-00793-7.

8. Semenza GL. HIF-1 and mechanisms of hypoxia sensing. Curr Opin Cell Biol. 2001;13:167-71.

9. Jiang BH, Semenza GL, Bauer C, Marti HH. Hypoxia-inducible factor 1 levels vary exponentially over a physiologically relevant range of $\mathrm{O}_{2}$ tension. Am J Physiol. 1996;271:C1172-1180.

10. Goossens GH, Jocken JWE, Blaak EE. Sexual dimorphism in cardiometabolic health: the role of adipose tissue, muscle and liver. Nat Rev Endocrinol. 2021;17:47-66. 